\title{
KONDISI METEOROLOGI, KLIMATOLOGI, DAN PERIKANAN DI KAWASAN WADUK CIRATA, JAWA BARAT: Analisis Awal Kemungkinan Dampak Pemanasan Global terhadap Perikanan Budidaya
}

\author{
I Nyoman Radiarta*), Anang Hari Kristanto*), dan Adang Saputra**) \\ *) Pusat Penelitian dan Pengembangan Perikanan Budidaya \\ J. Ragunan 20, Pasar Minggu, Jakarta Selatan 12540 \\ E-mail: radiarta@yahoo.com \\ **) Balai Penelitian dan Pengembangan Perikanan Budidaya Air Tawar \\ Jl. Sempur No. 1, Bogor 16154
}

(Naskah diterima: 5 Mei 2011; Disetujui publikasi: 5 September 2011)

\begin{abstract}
ABSTRAK
Pemanasan global adalah perubahan iklim yang dapat teridentifikasi melalui perubahan rata- rata yang terjadi pada jangka waktu yang relatif panjang. Perubahan ini disebabkan baik karena variasi kondisi alam maupun akibat dari aktivitas manusia (antropogenic). Pemanasan global diproyeksikan akan berpengaruh terhadap kondisi ekosistem, kondisi sosial dan ekonomi, dan meningkatnya tekanan terhadap sumber mata pencaharian yang berimplikasi pada penyediaan pangan. Bagi perikanan budidaya, pemanasan global dapat berpengaruh pada perubahan tingkat produktivitas, distribusi, komposisi spesies, dan lingkungan perairan sehingga dapat menyebabkan perubahan dalam operasional perikanan budidaya. Berdasarkan perkembangan isu tentang pemanasan global ini, penelitian dampak pemanasan global terhadap perikanan budidaya dirasakan sangat penting. Tujuan dari penelitian ini adalah untuk melihat kemungkinan adanya dampak pemanasan global terhadap aktivitas perikanan budidaya (ikan air tawar) di kawasan Waduk Cirata, Jawa Barat. Data utama yang dikumpulkan dalam penelitian ini diperoleh dari berbagai sumber meliputi data klimatologi, meteorologi, tutupan lahan dan karakteristik waduk. Analisis data yang ditampilkan dalam tulisan ini masih merupakan analisis awal yang lebih banyak diuraikan secara deskriptif melalui tampilan grafik. Hasil dari penelitian ini diharapkan dapat memberikan gambaran umum mengenai kemungkinan adanya dampak pemanasan global bagi perikanan budidaya air tawar khususnya di Waduk Cirata, sehingga nantinya dapat membantu dalam pengelolaan waduk yang lebih baik.
\end{abstract}

KATA KUNCl: meteorologi, klimatologi, budidaya ikan air tawar, pemanasan global, Waduk Cirata

ABSTRACT: Meteorology, climatology, and fisheries conditions in Cirata Reservoir, West Java: A preliminary analysis on possible impact of climate change to aquaculture. By: I Nyoman Radiarta, Anang Hari Kristanto, and Adang Saputra

Global warming is the change of climate condition that can be identified through long term average of its variability. The change could be caused by either natural condition or antropogenic activities. Climate change will influence the surrouding natural ecosystem, socio-economic of afffected communities, and inflict to the availability of livelihood related with food security. In term of aquaculture, climate change could 
impact the system to level of productivity, species distribution and composition, and environmental condition, and finally change the practices of aquaculture activities. Taking to the account of issues on climate change, research on possible impact of climate change to aquaculture has become an important discussion topic. The aim of this study was to investigate the possible impacts of climate change to freshwater aquaculture in Cirata Reservoir, West Java. The main data used in this study was collected from different sources including climatology, meteorology, land cover, characteristic of the reservoir. All data were then analyzed in order to observe the conectivity among them in relation with the climate condition. The result from this study was a preliminary analysis based on the availability of secondary data. The finding from this study could give a general overview on the possible impact of climate change to freshwater aquaculture especially in Cirata Reservoir.

\section{KEYWORDS: meteorology, climatology, freshwater fish aquaculture, climate change, Cirata Reservoir}

\section{PENDAHULUAN}

Intergovernmental Panel on Climate Change (IPCC, 2007) mendefinisikan pemanasan global adalah perubahan iklim yang terjadi pada jangka waktu yang panjang misalnya satu dekade ataupun lebih panjang lagi, dan dapat teridentifikasi dengan baik (misalnya menggunakan uji statistik). Perubahan ini dapat diakibatkan oleh variasi kondisi alam atau aktivitas manusia. IPCC dalam buku laporannya yang keempat telah memprediksi terjadinya perubahan suhu udara sampai pada akhir abad 21 (2009-2099), perubahan yang terjadi berkisar antara $1,8^{\circ} \mathrm{C}$ (estimasi untuk prediksi terendah- B1) sampai $4^{\circ} \mathrm{C}$ (estimasi untuk prediksi tertinggi- $\mathrm{AlFI}$ ) (IPCC, 2007). Pemanasan global yang terjadi dapat mempengaruhi variasi suhu udara/ air, cuaca, dan ketersediaan pasokan air (kualitas dan kuantitas). Dampak dari perubahan suhu dapat mempengaruhi tingkat produktivitas dari suatu ekosistem yang pada akhirnya dapat berdampak pada variasi waktu dan keberhasilan pola migrasi, pemijahan, dan kelimpahan (Walther et al., 2002; Beukema \& Dekker, 2005; Saitoh et al., 2011). Pemanasan global diproyeksikan akan berpengaruh terhadap kondisi ekosistem, kondisi sosial dan ekonomi, dan meningkatnya tekanan terhadap sumber mata pencaharian yang berimplikasi pada penyediaan bahan pangan.

Kondisi iklim akan selalu bervariasi berdasarkan waktu dan tempat. Sangat jelas perbedaannya antara perubahan iklim dan variasi iklim. Perubahan iklim adalah tren (fluktuasi) iklim selama kurun waktu yang cukup panjang, paling sedikit sekitar 20 tahun, sedangkan variasi iklim mengacu kepada fluktuasi iklim setiap tahunnya (Blenckner, 2005). Sehubungan dengan pemanasan global yang terjadi, masih adanya ketidakpastian mengenai berapa besar, seberapa cepat dan di mana saja iklim akan berubah secara signifikan. Untuk melihat perubahan iklim yang terjadi, para ahli telah melakukan berbagai cara untuk mengkarakterisasi perubahan yang terjadi baik regional maupun global. Satu pendekatan yang umum digunakan adalah melalui zone indek. El Niño Southern Oscillation (ENSO) indek merupakan satu zone indeks yang sangat populer di wilayah Pasifik tropis, yang dapat berdampak pada perubahan lingkungan perairan dan daratan. Pendekatan menggunakan zone indeks ini secara umum sangat bermanfaat untuk melihat dampak perubahan lingkungan terhadap perubahan iklim. Hal ini disebabkan indek ini mengintegrasikan berbagai variabel iklim (misalnya suhu, curah hujan, dan tutupan awan) dan memungkinkan melihat variasinya secara tahunan untuk iklim regional.

Penelitian dampak pemanasan global terhadap perikanan budidaya masih sangat terbatas. Beberapa pustaka yang ada umumnya masih bersifat review tentang kemungkinan dampak yang ditimbulkan baik dampak secara langsung maupun tidak langsung (Bardach, 1989; Meisner \& Shuter, 1992; Harley et al., 2006; Cochrane et al., 2009). Secara global, Handisyde et al. (2006) telah melakukan analisis kemungkinan dampak dari perubahan iklim global terhadap perikanan budidaya. Parameter utama yang digunakan dalam analisis tersebut meliputi kondisi klimatologi dan perairan (suhu udara, presipitasi, penaikan muka air (sea level rise), kondisi ekstrim, variasi iklim, dan arus laut), 
dan kondisi perikanan budidaya (produksi, mata pencaharian, dan ketersediaan minyak ikan dan makanan ikan). Meskipun dilengkapi dengan contoh kasus di Bangladesh, penelitian ini hanya memberikan gambaran secara global kemungkinan dampak yang ditimbulkan dari perubahan iklim terhadap perikanan budidaya. Dari penelitian ini, disarankan agar melakukan kajian yang lebih spesifik, sehingga nantinya dapat memberikan kontribusi yang nyata terhadap pemahaman kita mengenai bagaimana pemanasan global berdampak terhadap sumberdaya perikanan budidaya. Dampak dari perubahan iklim khususnya pengaruh langsung dari zone indeks: El Niño dan La Niña terhadap budidaya kekerangan (Japanese scallop) telah didemontrasikan oleh Baba et al. (2009). Mereka menyimpulkan bahwa, terjadinya El Niño dapat mempengaruhi rendahnya kelimpahan spat yang tersedia, sedangkan La Niña menunjukkan pengaruh yang sangat signifikan terhadap reproduksi dan pertumbuhan dari scallop. Hal ini menunjukkan bahwa penelitian lebih lanjut dari dampak pemanasan global terhadap perikanan budidaya merupakan suatu tantangan dan perlu dikaji lebih mendalam. Hasil kajian tersebut tentunya akan bermanfaat guna dapat diambil tindakan adaptasi terhadap aktivitas perikanan budidaya yang pada akhirnya dapat berkontribusi pada usaha perikanan budidaya yang berkelanjutan.

Data klimatologi dan meteorologi (iklim) sangat berperan bagi kegiatan perikanan. Lama penyinaran dan suhu udara sangat mempengaruhi kondisi suhu perairan dan secara langsung akan berdampak terhadap tingkat produktivitas dari suatu perairan dan tingkat pertumbuhan dari biota yang dibudidayakan. Data iklim telah dimanfaatkan dibidang perikanan budidaya (Kapetsky, 2000). Namun, belum banyak upaya yang dilakukan sehubungan dengan akuisisi dan pembentukan aplikasi data iklim sebagai satu media untuk perikanan budidaya. Munculnya isu pemanasan global belakangan ini membuat perspektif yang cukup menarik dalam hal pemanfaatan data iklim. Data tersebut jika dikaji secara komprehensif dan dihubungkan dengan kondisi perairan tentunya akan memberikan gambaran yang lebih baik. Sebagai contoh terjadinya kematian ikan di Waduk Cirata, umumnya kajian yang ada bersifat parsial dari aspek kondisi kualitas perairan saja (Abery et al., 2005; Hayami et al., 2008), belum melihat keterkaitannya dengan kondisi iklim secara global.

Secara umum dampak secara langsung yang mungkin ditimbulkan dengan perubahan suhu (udara/ air) adalah kelayakan dari suatu jenis ikan untuk dibudidayakan di lokasi tertentu, sedangkan dampak tidak langsung berupa pengaruh terhadap kandungan oksigen, penyakit, dan terjadinya kelimpahan alga beracun (De Silva \& Soto, 2009). Pemanasan global juga dapat berpengaruh terhadap fluktuasi muka air kawasan waduk/ danau disebabkan karena perubahan curah hujan, yang tentunya sangat berpengaruh bagi keberlangsungan kegiatan perikanan di kawasan waduk/ danau. Melihat isu- isu yang ada tersebut, penelitian spesifik dampak pemanasan global terhadap perikanan budidaya (misalnya dampaknya terhadap timbulnya penyakit, produktivitas perikanan air tawar ataupun budidaya laut) sangat diperlukan guna dapat memberikan dukungan data dan informasi yang relevan mengenai dampak pemanasan global terhadap perikanan budidaya.

Tujuan dari penelitian ini adalah untuk melakukan analisis kemungkinan adanya dampak pemanasan global terhadap aktivitas perikanan budidaya ikan air tawar di Waduk Cirata, Jawa Barat. Analisis dilakukan berdasarkan data sekunder yang dikumpulkan dengan melihat dua aspek (filter) yang dapat mempengaruhi besarnya dampak pemanasan global terhadap ekosistem waduk. Analisis yang disajikan dalam tulisan ini adalah analisis awal yang dibahas dengan melihat keterkaitan antara beberapa kondisi baik di dalam maupun luar waduk terhadap kemungkinan adanya dampak pemanasan global.

\section{BAHAN DAN METODE}

Penelitian ini telah dilakukan di Waduk Cirata, Jawa Barat (Gambar 1). Lokasi penelitian terletak pada posisi $6^{\circ} 44^{\prime} \mathrm{LS} ;$ 107 $^{\circ} 18^{\prime}$ BT. Waduk ini merupakan deretan tiga waduk besar yang terletak di daerah aliran sungai (DAS) Citarum. Dua waduk lainnya adalah Waduk Jatiluhur dan Sanguling. Sejak pertama kali dioperasikan yaitu tahun 1988, aktivitas perikanan budidaya dengan menggunakan keramba jaring apung (KJA) telah berkembang di waduk ini (Soemarwoto et al., 1990).

Data utama yang digunakan dalam penelitian ini adalah data sekunder. Data ini 


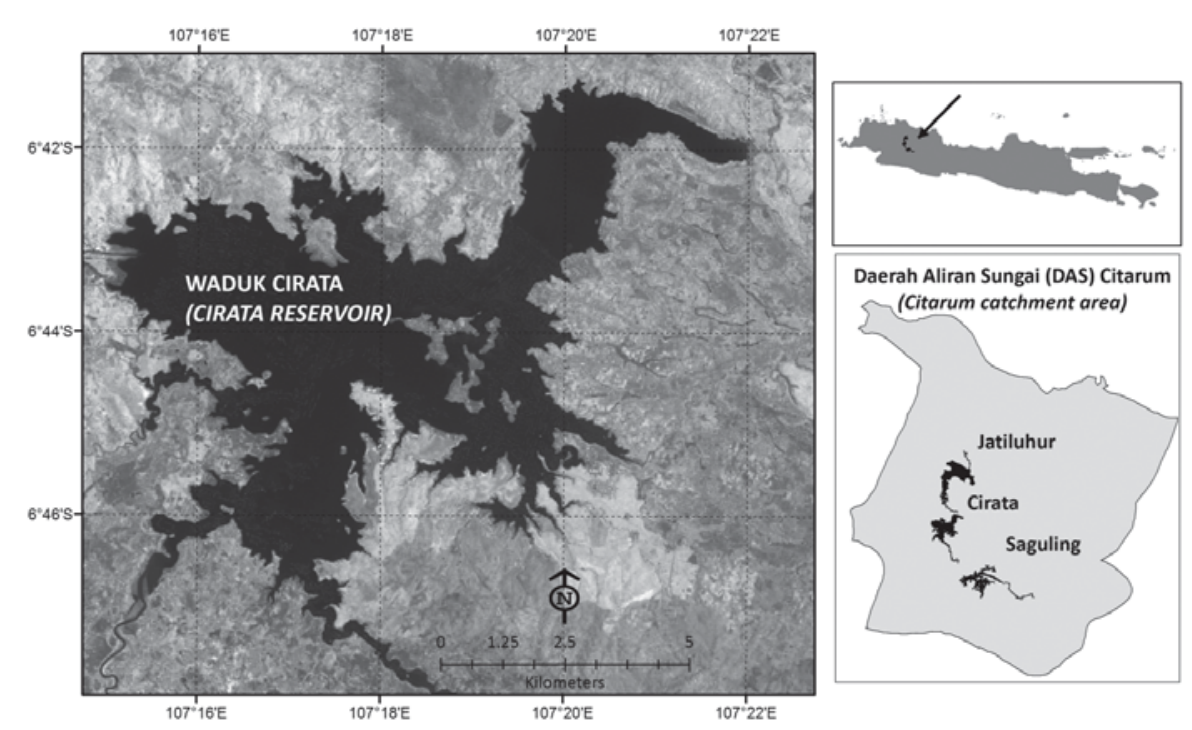

Gambar 1. Lokasi penelitian di Waduk Cirata, Jawa Barat

Figure 1. Study area at Cirata Reservoir, West Java

dikumpulkan dari instansi terkait, studi pustaka (publikasi ilmiah), dan sumber dari internet. Instansi terkait yang berhubungan dengan dengan pengelolaan waduk Cirata di antaranya Dinas Kelautan dan Perikanan (DKP), Badan Pengelola Waduk Cirata (BPWC), dan Unit Pembangkit Jawa- Bali (UPJB). Data yang dikumpulkan dalam penelitian ini meliputi: kondisi iklim (suhu udara minimum, suhu udara maksimum, suhu udara rata- rata, dan curah hujan), kondisi lahan waduk, dan kondisi aktivitas budidaya ikan. Data spasial klimatologi untuk kawasan DAS Citarum diperoleh dari World Climatology (Hijmans et al., 2005; http:/ / www. worldclim.org/ ).

Analisis data dalam penelitian ini mengadopsi metode yang dikemukakan oleh Blenckner (2005). Menurut Blenckner (2005), konsepsual model kemungkinan dampak perubahan/ variasi iklim terhadap ekosistem waduk dapat dianalisis dari dua aspek (filter) penting yaitu aspek karakteristik lokasi dan karakteristik waduk (Gambar 2). Berdasarkan kedua aspek ini, data yang telah dikumpulkan kemudian dilihat hubungannya dan dibahas secara deskriptif yang disertai dengan gambar.

\section{HASIL DAN BAHASAN}

Respons ekosistem waduk terhadap dampak pemanasan global akan berbeda- beda sesuai dengan karakteristik dari DAS dan waduk. Kombinasi aspek dari luar dan dalam waduk (Blenckner, 2005) akan memberikan perspektif yang komprehensif mengenai respons dari ekosistem waduk. Hasil yang ditampilkan dalam penelitian hanya merupakan suatu kajian awal dengan memperhatikan trend perkembangan lingkungan dan kondisi waduk yang kiranya dapat dikaitan dengan berkembangnya isu mengenai pemanasan global yang terjadi sekarang ini (IPCC, 2007).

\section{Karakteristik Lokasi (Kondisi Luar Waduk)}

Waduk Cirata merupakan waduk yang terletak di DAS Citarum, berlokasi sekitar 40 $\mathrm{km}$ dari arah Barat Laut Kota Bandung. Waduk ini berada pada ketinggian sekitar $221 \mathrm{~m}$ dari permukaan laut (dpl). Maksimum kedalaman waduk adalah 125 m (rata- rata kedalaman 35 $\mathrm{m}$ ) dengan volume air sekitar $2.2 \mathrm{~km}^{3}$ (Hayami et al., 2008). Lokasi ketinggian waduk dari permukaan laut tentunya akan mempengaruhi volume air yang masuk. Waduk yang berlokasi cukup tinggi hanya memperoleh sumber air berasal dari curah hujan (precipitation) sedangkan waduk yang terletak di dataran rendah memperoleh air dari aliran sungai dan air tanah. Blenckner (2005) mengemukakan bahwa danau yang berlokasi di ketinggian umumnya berukuran kecil, memiliki kecerahan yang tinggi, jumlah spesies ikan terbatas, dan 


\section{Perubahan iklim (Climate change) Variasi iklim (Climate variability)}

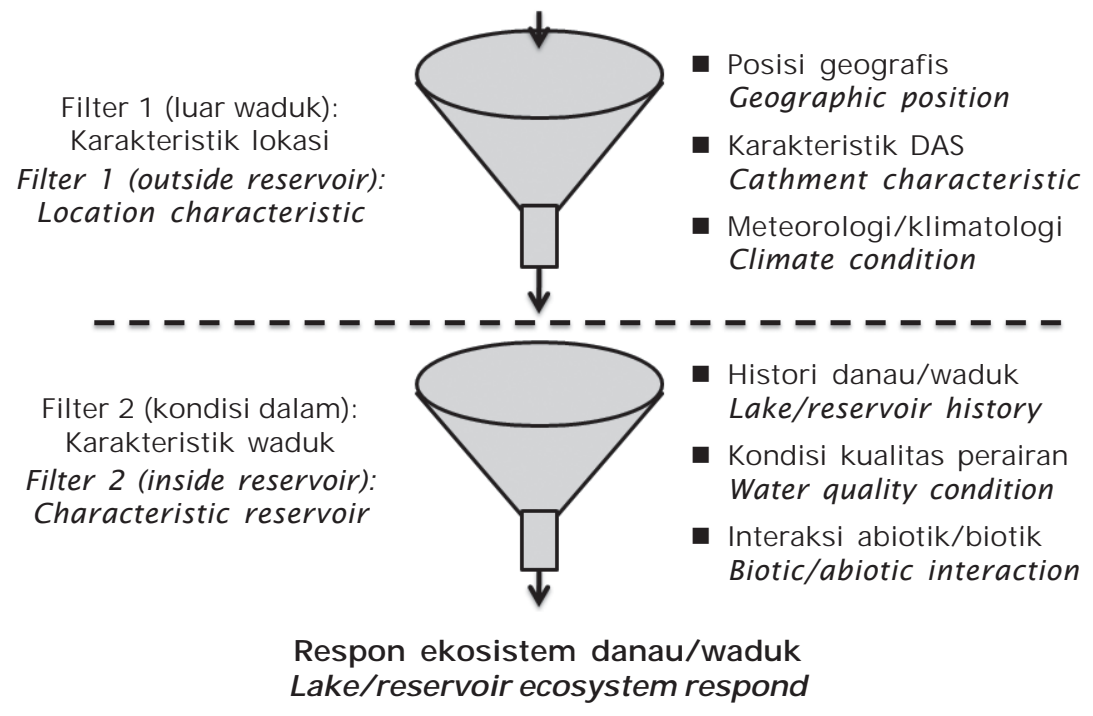

Gambar 2. Model analisis data kemungkinan dampak perubahan/variasi iklim terhadap ekosistem waduk.

Figure 2. Modeling approach of possible impact of climate variability on reservoir ecosystem.

rendahnya dampak dari aktivitas manusia dibandingkan dengan danau yang berlokasi di daratan rendah. Dilihat dari sisi ketinggian, Waduk Cirata dapat dikategorikan berada pada daratan yang tidak terlalu tinggi. Sumber air waduk ini umumnya berasal dari aliran Sungai Citarum, yang merupakan aliran sungai terbesar di Jawa Barat. Hasil analisis data curah hujan di kawasan DAS Citarum menunjukkan bahwa terdapat dua musim di kawasan ini yaitu musim kering pada bulan Mei- September dan musim penghujan pada bulan Oktober- April (Gambar 3). Rata- rata presipitasi bulanan adalah 67- 155 mm pada musim kering dan 169- 328 $\mathrm{mm}$ pada musim penghujan (Hayami et al., 2008).

Dampak langsung dari adanya pemanasan global adalah terjadinya perubahan suhu udara. Perubahan suhu udara secara spasial di kawasan DAS Citarum cukup bervariasi (Gambar 4). Suhu udara terendah terjadi sekitar bulan Juli, sedangkan suhu udara maksimum terjadi bulan Agustus- September. Data suhu udara dari stasiun Badan Meteorologi Klimatologi dan Geofisik (BMKG) dan UPJB umumnya dapat diperoleh secara berkelanjutan (time series), sedangkan data suhu air dari suatu kawasan waduk sangat terbatas ketersediaannya. Variasi suhu udara ini dapat dijadikan data proxy untuk menduga fluktuasi suhu air waduk. Seperti yang dilaporkan oleh Boyd \& Pine (2006), bahwa fluktuasi rata- rata suhu udara bulanan identik dengan fluktuasi rata- rata suhu air. Hal ini berimplikasi bahwa perubahan yang terjadi pada suhu udara setiap musimnya akan mempengaruhi suhu air dan pertumbuhan dari biota air. Suhu udara bulanan di Waduk Cirata cukup berfluktuasi (Gambar 5a). Kisaran suhu udara hasil pemantauan stasiun klimatologi UPJB adalah antara $20^{\circ} \mathrm{C}-30^{\circ} \mathrm{C}$. Dari data histori yang ada (tahun 2003- 2009), menunjukkan bahwa terjadi kondisi yang cukup ekstrim di tahun 2004 dan 2007. Pada tahun 2004, suhu udara meningkat secara signifikan mencapai lebih dari $35^{\circ} \mathrm{C}$. Kondisi ini sangat berhubungan dengan terjadinya El Niño di kawasan tropis (http:// w w w. c p c.noaa.gov/products/ analysis_monitoring/ensostuff/ens). Sebaliknya tahun 2007 suhu udara menurun drastis mencapai sekitar $17^{\circ} \mathrm{C}$. Kondisi ini jika dikaitkan dengan zone indek di kawasan tropis adalah bersamaan dengan terjadinya La Niña. Kedua contoh kondisi ekstrim ini, merupakan 


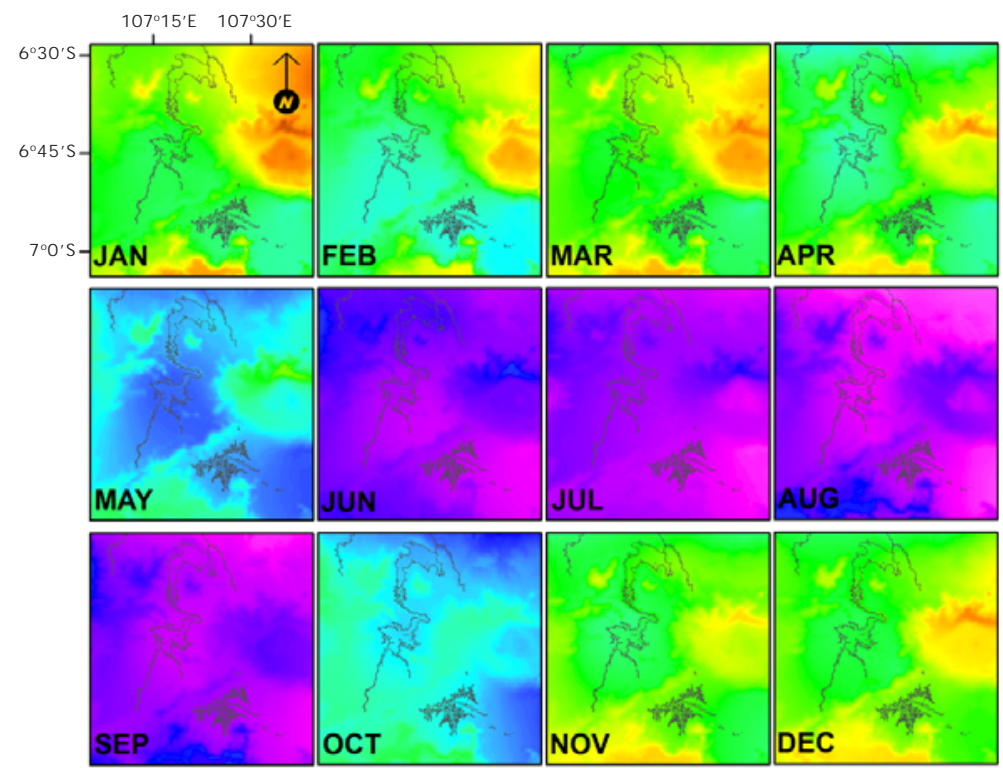

Presipitasi (Precipitation) (mm)

\begin{tabular}{lr}
\hline $\mathbf{0}$ & $\mathbf{5 0 0}$ \\
Rendah (Low) & Tinggi (High)
\end{tabular}

Gambar 3. Kondisi presipitasi (mm) di kawasan DAS Citarum

Figure 3. Precipitation $(\mathrm{mm})$ condition in Citarum Watershed

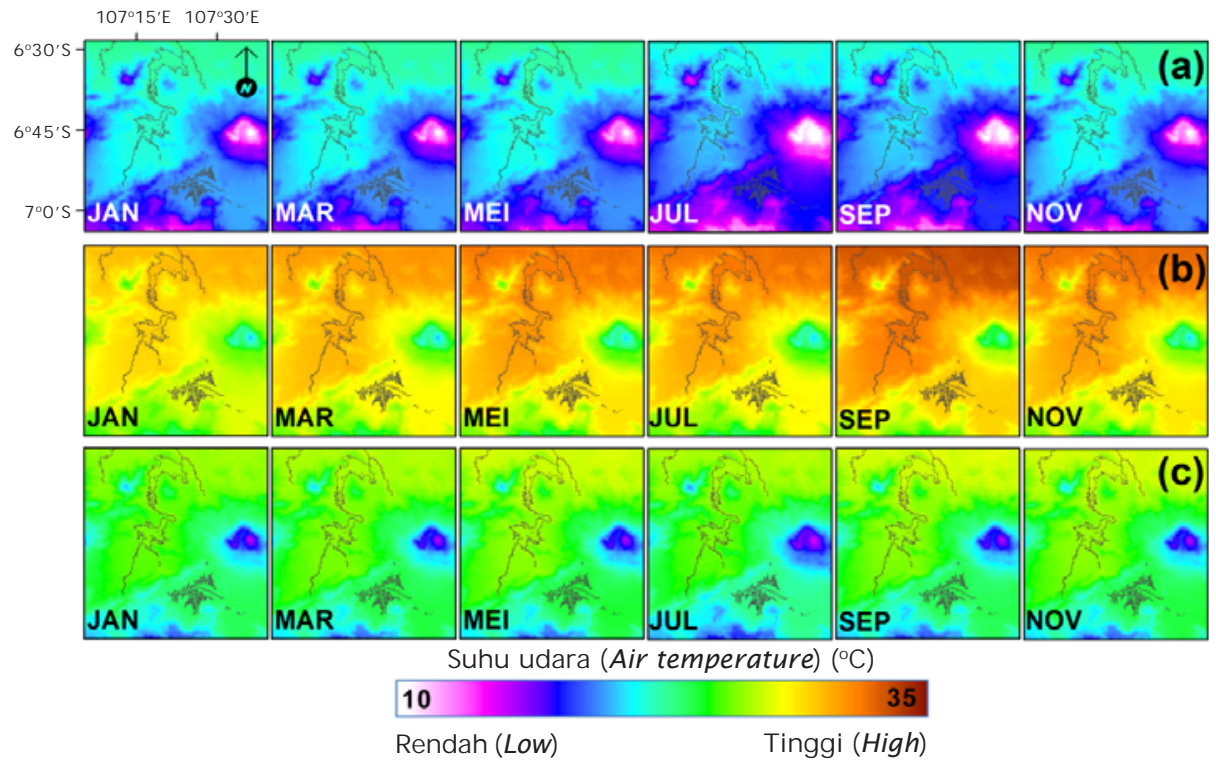

Gambar 4. Kondisi suhu udara $\left({ }^{\circ} \mathrm{C}\right)$ di kawasan DASCitarum: (a) suhu minimum, (b) suhu maksimum, dan (c) suhu rata- rata

Figure 4. Water temperature $\left({ }^{\circ} \mathrm{C}\right)$ condition in Citarum Watershed: (a) minimum temperature, (b) maximum temperature, and (c) average temperature 


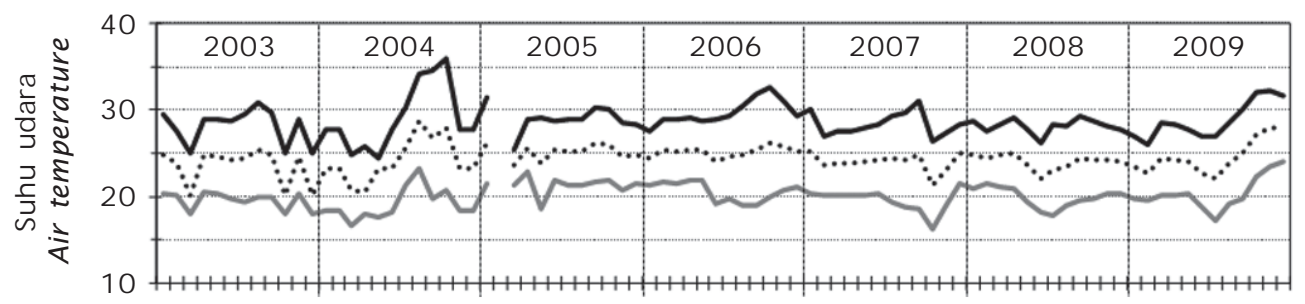

(a)

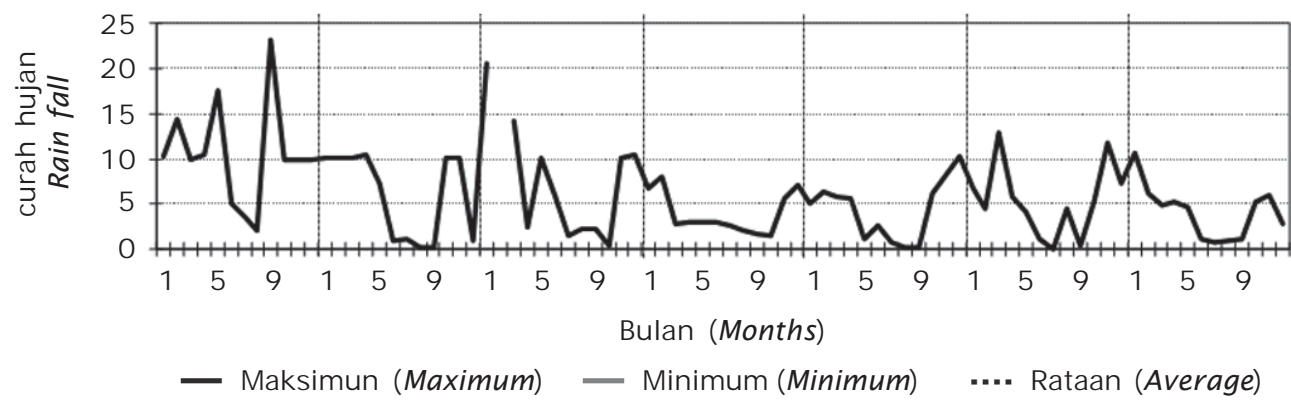

(b)

Gambar 5. Kondisi suhu udara (a) dan curah hujan (b) di Waduk Cirata dari tahun 2003- 2009

Figure 5. Air temperature condition (a) and rain fall (b) in Cirata Reservoir from 2003-2009

indikasi penting yang dapat dikaitkan dengan adanya dampak dari pemansan global yang terjadi di kawasan Waduk Cirata. Kondisi ini jika dikaitkan dengan kondisi perikanan budidaya tentunya akan memberikan prespektif yang berbeda.

Kondisi curah hujan yang terjadi di kawasan Waduk Cirata hasil pemantauan stasiun UPJB menunjukkan fluktuasi yang cukup tinggi (Gambar 5b). Secara umum, curah hujan yang tinggi terjadi sekitar bulan OktoberApril setiap tahunnya, dengan curah hujan maksimum ditemukan pada tahun 2003. Tingginya curah hujan yang terjadi dapat mempengaruhi terjadinya penurunan suhu air yang jika dibarengi dengan terjadinya hembusan angin yang kencang akan memicu terjadinya pengadukan kolom air (terjadinya umbalan, upwelling) yang sering berimplikasi pada terjadinya kematian ikan (Krismono et al., 2001).

Kondisi tutupan lahan di sekitar area resapan (catchmen area) merupakan aspek luar waduk yang berperan penting bagi kondisi lingkungan perairan dalam waduk (Gambar 6). Masing-masing jenis tutupan lahan akan memberikan pengaruh berbeda terhadap kondisi perairan waduk (Xiaoyan et al., 2002). Padatnya pemukiman dan aktivitas pertanian yang ada di sekitar Waduk Cirata dapat memicu terjadinya peningkatan polusi perairan yang diakibatkan karena pasokan limbah aktivitas rumah tangga, industri, dan pertanian yang terbawa dari aliran sungai masuk ke dalam waduk. Indeks kesesuaian kualitas perairan di Waduk Cirata menunjukkan kondisi yang lebih baik dibandingkan dengan Waduk Saguling (Soemarwoto et al., 1990). Hal ini disebabkan karena pasokan limbah yang berasal dari Kota Bandung, Cimahi, dan Padalarang masuk di Waduk Saguling melalui Sungai Citarum sangat besar.

\section{Karakteristik Waduk (Kondisi Dalam Waduk)}

Aktivitas yang terdapat dalam kawasan waduk juga akan memberikan respons yang cukup signifikan terhadap kemungkinan dampak pemanasan global terhadap ekosistem waduk. Waduk Cirata yang dibangun pada tahun 1988 bertujuan untuk memenuhi tenaga listrik dan pengendalian banjir. Namun sejalan dengan perkembangan waktu, aktivitas penunjang semakin berkembang di antaranya perikanan dan pariwisata. Kegiatan perikanan budidaya di waduk ini telah dilakukan dengan menggunakan KJA (Costa- Pierce, 1998). Ikan yang umumnya dibudidayakan adalah ikan mas (Cyprinus carpio) dan nila (Oreochromis niloticus) (Abery et al., 2005). Pengelolaan waduk untuk kegiatan perikanan ditujukan 


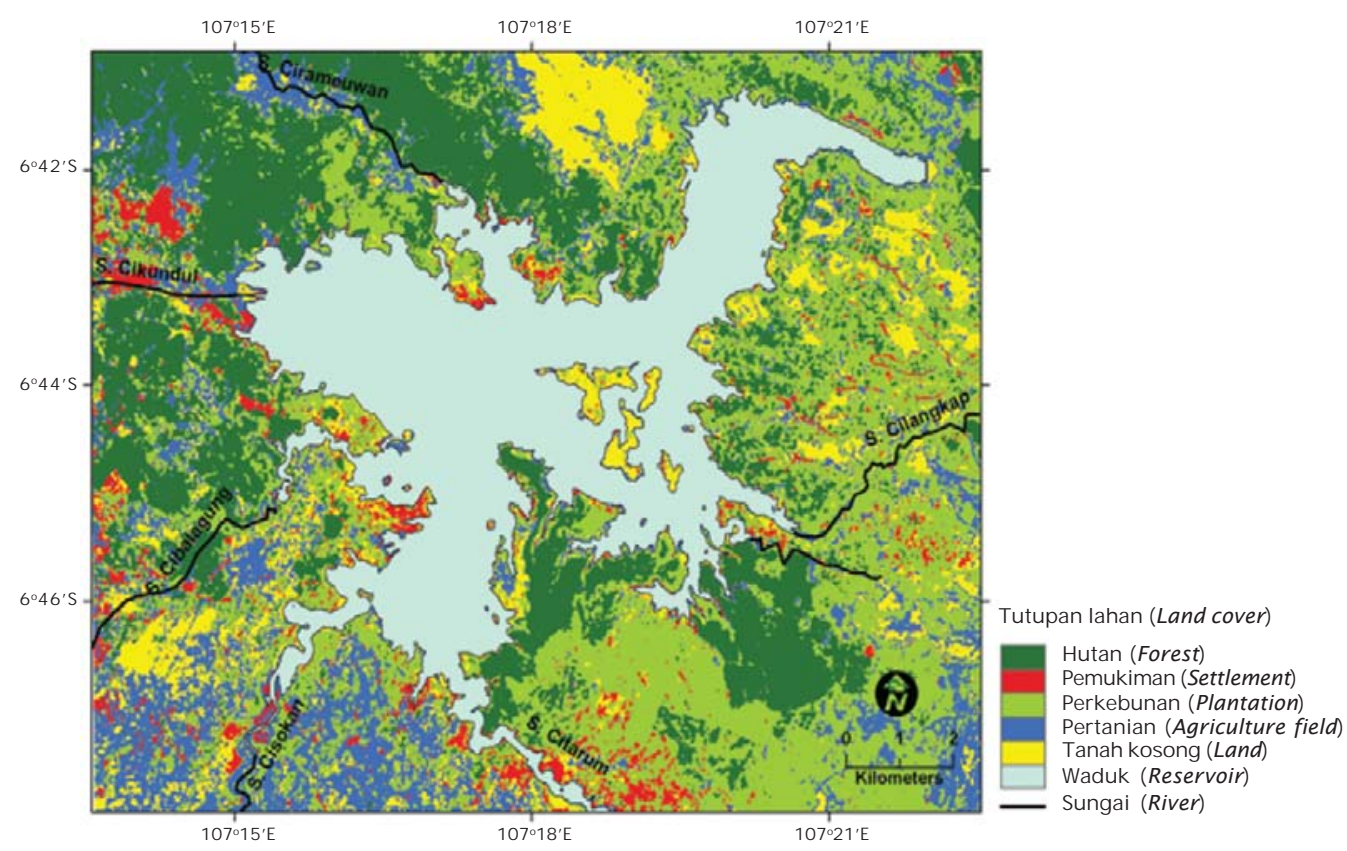

Gambar 6. Tutupan lahan di kawasan Waduk Cirata (Sumber: Radiarta \& Ardi, 2009)

Figure 6. Land cover condition around Cirata Reservoir area (Source: Radiarta \& Ardi, 2009)

(a) LANDSAT ETM+ 29 April 2002

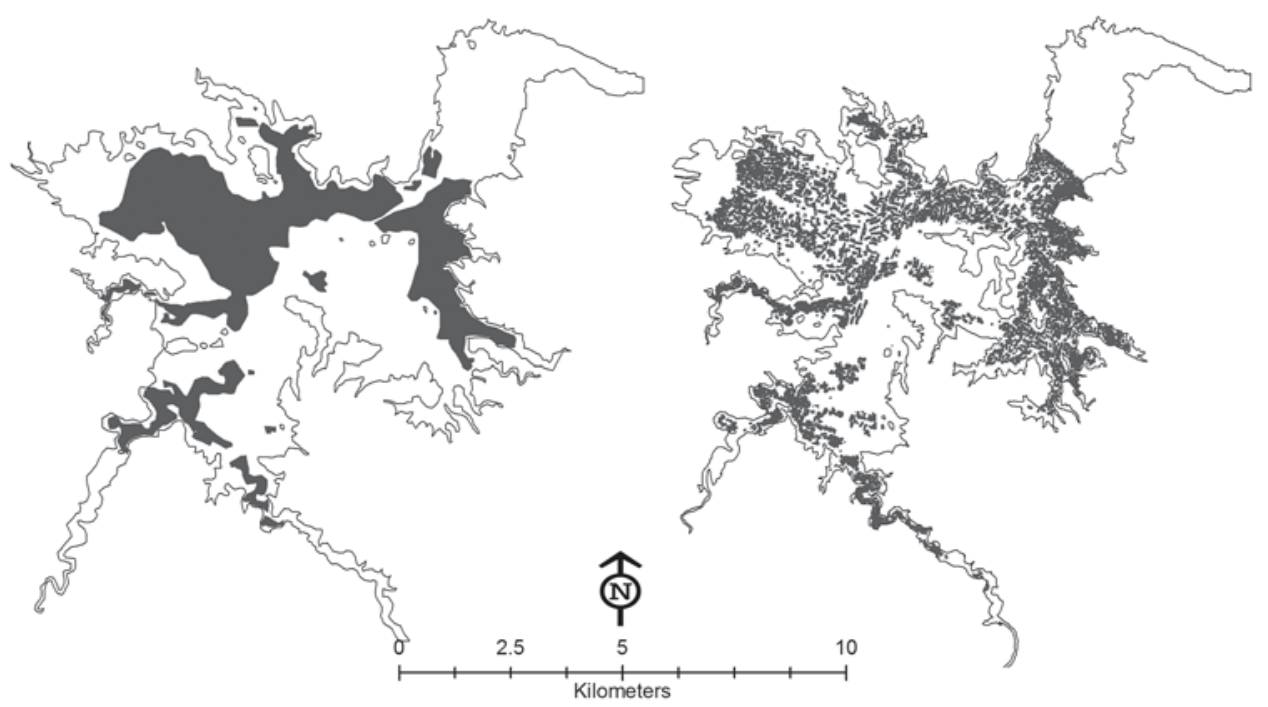

Gambar 7. Distribusi KJA di Waduk Cirata pada waktu pemantauan yang berbeda: (a) Landsat ETM+ akuisisi tanggal 29 April 2002 dan (b) ALOSAVNIR- 2 akuisisi tanggal 27 September 2008 (Sumber: Radiarta et al., 2005; Radiarta \& Ardi 2009)

Figure 7. Cage culture distribution in Cirata Reservoir at different observation time: (a) Landsat ETM+ aquired on April 29, 2002 and (b) ALOS AVNIR-2 aquired on September 27, 2008 (Source: Radiarta et al., 2005; Radiarta \& Ardi 2009) 
untuk mengoptimalkan produksi ikan dan menjaga kelestarian sumberdaya perikanan serta lingkungan sehingga dapat dimanfaatkan secara berkelanjutan oleh masyarakat sekitar kawasan waduk. Perkembangan jumlah KJA yang ada di Waduk Cirata menunjukkan jumlah yang telah melebihi daya dukung waduk tersebut (Gambar 7). Hasil analisis citra satelit menunjukkan peningkatan tutupan KJA yang sangat signifikan (Radiarta \& Ardi, 2009). Penempatan KJA yang ada sekarang ini juga sudah tidak sesuai lagi dengan zonasi pemanfaatan lahan yang telah ditetapkan sebelumnya (Radiarta et al., 2005). Kondisi ini dapat disebabkan karena lemahnya managemen pengelolaan waduk yang ada (Krismono \& Wahyudi, 2002).

Peningkatan jumlah KJA ini dapat menyebabkan penurunan mutu lingkungan di dalam waduk. Beberapa hasil penelitian menunjukkan bahwa kandungan oksigen yang masih layak untuk aktivitas budidaya ikan di Waduk Cirata hanya tersedia sampai pada kedalaman maksimum sekitar 7 m sedangkan perubahan suhu secara drastis (thermocline) ditemukan sekitar kedalaman 5- 7 m (Hayami et al., 2008). Kondisi ini menunjukkan jika terjadi perubahan iklim yang ekstrim akan cepat memacu terjadinya pengadukan yang membawa gas- gas beracun dari dasar waduk kepermukaan sehingga dapat menyebabkan kematian ikan. Gambar 8 menyajikan data variasi jumlah KJA, produksi ikan secara total dan per KJA dan frekuensi terjadinya kematian ikan dari tahun 1988-2002. Produksi total maksimum tercatat tahun 1997, sedangkan produksi maksimum per KJA tercatat tahun 1994. Peningkatan KJA setiap tahunnya tidak mendorong peningkatan produksi namun sebaliknya, produksi ikan semakin menurun (Gambar 8). Hal ini dapat disebabkan karena kondisi lingkungan dalam waduk sudah tidak dapat mendukung secara maksimal untuk kegiatan perikanan budidaya dengan KJA. Frekwensi kejadian kematian ikan selalu ditemukan setiap tahunnya dengan tingkat kematian tersebar ditemukan tahun 1995. Tahun tersebut merupakan periode La Niña.

\section{Tantangan Penelitian Ke Depan}

Dengan memperhatikan dua aspek (dari luar dan dalam) yang dapat memicu respon ekosistem waduk terhadap dampak pemanasan global yang terjadi, masih terbuka peluang yang sangat besar untuk melakukan kajian-kajian yang lebih spesifik dan berkelanjutan. Sehingga nantinya ketersediaan data kondisi lingkungan perairan dapat dipadukan dengan data iklim yang tersedia. Kajian lingkungan perairan sehubungan dengan kondisi iklim global ini telah pula dilakukan oleh Balai Penelitian dan Pengembangan Perikanan Air Tawar mulai tahun 2010 (Adang Saputra, komunikasi

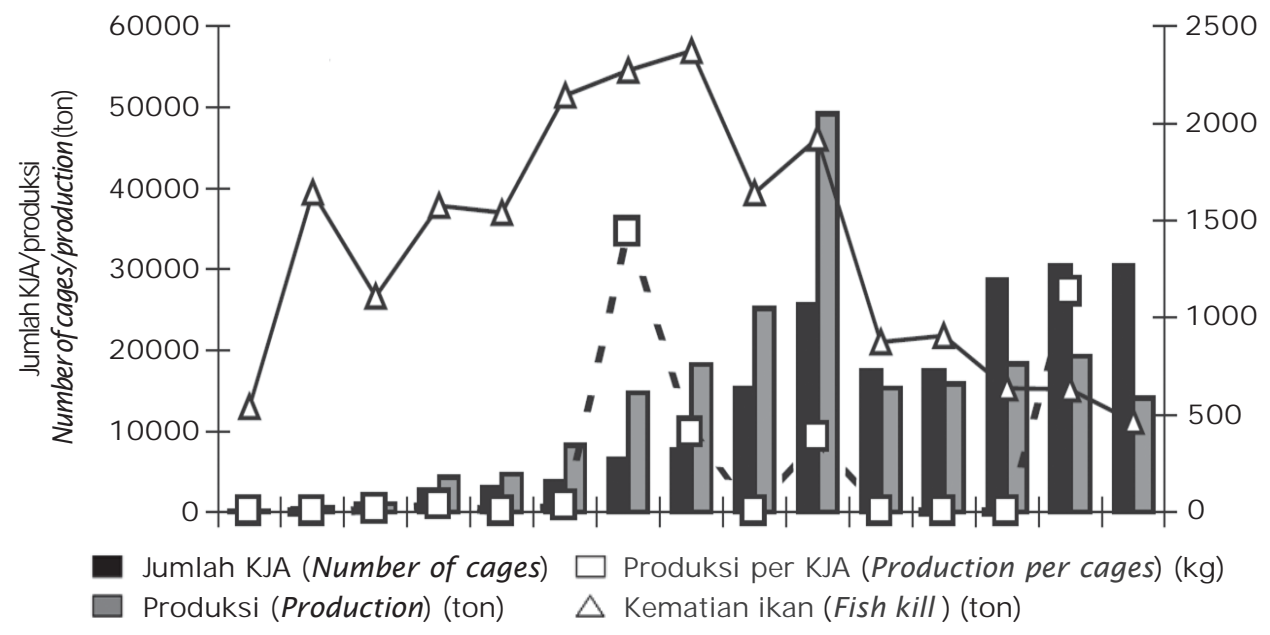

Gambar 8. Variasi perubahan jumlah KJA, produksi per KJA, produksi total dan frekuensi kematian ikan di Waduk Cirata, Jawa Barat (Sumber: Abery et al., 2005)

Figure 8. Variation on number of cage culture, cage culture production, total production, and fish kill frequency in Cirata Reservoir, West Java (Source: Abery et al., 2005) 
pribadi). Kegiatan ini mengumpulkan data kondisi kualitas perairan secara vertikal dan horizontal yang direncanakan selama 5 kali pengambilan data lapangan dalam satu tahun dan direncanakan selama 4 tahun berjalan, sampai tahun 2014. Ketersediaan data ini tentunya akan sangat membantu dalam memberikan gambaran secara nyata kondisi Waduk Cirata guna mendukung pengelolaan waduk yang lebih baik.

Untuk memperoleh hasil kajian yang komprehensif tentang kemungkinan dampak pemanasan global terhadap ekosistem waduk masih dirasakan sangat kurang dalam pelaksanaannya, hal ini disebabkan karena beberapa alasan yaitu (Blenckner, 2005):

(1) Ketersediaan data yang berkelanjutan (time series) yang kadang kala sulit diperoleh terutama data kondisi lingkungan perairan. Kalaupun data perikanan tersedia, umumnya masih bersifat parsial.

(2) Koordinasi lintas sektoral antar berbagai bidang ilmu masih terhambat dalam pelaksanaannya.

(3) Hasil- hasil penelitian yang kurang signifikan kadangkala susah untuk ditemukan, yang kemungkinan hasil tersebut dapat dikaitkan dengan kondisi iklim yang terjadi.

(4) Kombinasi pemanfataan model ekosistem dengan data histori masih belum banyak dianalisis.

Selain keempat hambatan tersebut, tentunya masih terdapat hambatan yang lebih spesifik, namun kondisi ini menjadikan tantangan tersendiri dan membuka peluang penelitian pemanasan global. Metode yang sangat mungkin dilakukan untuk bidang budidaya perikanan yaitu dengan pemodelan, seperti yang telah berkembang dibidang lainnya (pertanian, perikanan tangkap, dII)

\section{KESIMPULAN}

Kajian kemungkinan dampak pemanasan global terhadap ekosistem waduk tidak hanya dipengaruhi oleh kondisi luar ekosistem, namun juga harus memperhatikan interaksi dalam waduk itu sendiri. Dengan memperhatikan kedua aspek tersebut tentunya akan memberikan analisis yang lebih komprehensif mengenai respon waduk terhadap pemanasan global. Penelitian ini dilakukan untuk mensintesis kondisi Waduk Cirata dilihat baik aspek dari luar dan dalam terhadap kemungkinan dampak pemanasan global. Analisis awal ini memberikan gambaran yang cukup menarik terhadap isu pemanasan global yang terjadi. Namun untuk dapat memberikan hasil analisis yang lebih spesifik masih diperlukan tambahan histori data baik dari aspek iklim dan perikanan. Hasil dari penelitian ini diharapkan dapat menambah wawasan sehingga nantinya dapat diimplementasi dilapangan guna mencegah akibat yang lebih buruk dari adanya dampak pemanasan global.

\section{UCAPAN TERIMA KASIH}

Penulis mengucapkan terima kasih kepada tim survei pemanasan global Pusat Penelitian dan Pengembangan Perikanan Budidaya yang telah membantu kelancaran pengumpulan data. Penelitian ini merupakan bagian dari penelitian "dampak pemanasan global terhadap perikanan budidaya" Pusat Penelitian dan Pengembangan Perikanan Budidaya T.A. 2010.

\section{DAFTAR ACUAN}

Abery, N.W., Sukadi, F., Budhiman, A.A., Kartamihardja, E.S., Koeshendrajana, S., Buddhiman, \& De Silva, S.S. 2005. Fisheries and cage culture of three reservoirs in West Java, Indonesia: a case study of ambitious development and resulting interactions. Fisheries Management and Ecology, 12: 315-330.

Baba, K., Sugawara, R., Nitta, H., Endou, K., \& Miyazono, A. 2009. Relationship between spat density, food availability, and growth of spawners in cultured Mizuhopecten yessoensis in Funka Bay: concurrence with ENSO. Canadian Journal of Fisheries and Aquactic Sciences, 12: 6- 17.

Bardach, J.E. 1989. Global warming and the coastal zone. Climatic Change, 15: 117150.

Beukema, J.J. \& Dekker, R. 2005. Decline of recruitment success in cockles and other bivalve in the Wadden Sea: possible role of climate change, predation on postlarvae and fisheries. Marine Ecology Progress Series, 287: 149- 167.

Blenckner, T. 2005. A cenceptual model of climate- related effects on lake ecosystems. Hydrobioilogia, 533: 1- 14.

Byod, C.E. \& Pine, H. 2006. Application of agrometeorology to aquaculture and fisheries. WMO/CAgM Guide to Agricultural 
Meteorological Practices (GAMP) Chapter 14. Didownload tanggal28 Juli 2011: http:/ / www.agrometeorology.org/files- folder/ repository/gamp_chapt14final.pdf.

Cochrane, K., De Young, C., Soto, D., \& Bahri, T. (eds). 2009. Climate change implication for fisheries and aquaculture: overview of current scientific knowledge. FAO Fisheries and Aquaculture Technical Paper. No. 530. Rome, FAO, $212 \mathrm{pp}$.

Costa- Pierce, B.A. 1998. Constraints to the sustainability of cage aquaculture for resettlement from hydropower dams in Asia: an Indonesian case study. J. of Environment and Development, 7: 333- 363.

De Silva, S.S. \& Soto, D. 2009. Climate change and aquaculture: potential impact, adaptation and mitigation. In Cochrane, K., De Young, C., Soto, D., \& Bahri, T. (eds). Climate change implication for fisheries and aquaculture: overview of current scientific knowledge. FAO Fisheries and Aquaculture Technical Paper. No. 530. Rome, FAO, p. 151- 212.

Harley, C.D.G., Hughes, A.R., Hultgren, K.M., Miner, B.G., Sorte, C.J.B., Thornber, C.S., Rodriguez, L.F., Tomanek, L., \& Williams, A.L., 2006. The impact of climate change in coastal marine systems. Ecology Letters, 9: 228- 241.

Handisyde, N.T., Ross, L.G., Badjeck, M- C., \& Allison, E.H. 2006. The effects of climate change on world aquaculture: a global perspective. Available online at www. aquacultur.stir.ac.uk/ GISAP/gis- group/ climate.php.

Hayami, Y., Ohmori, K., Yoshino, K., \& Garno, Y.S., 2008. Observation of anoxic water mass in a tropical reservoir: the Cirata Reservoir in Java, Indonesia. Limnology, 9: 8187.

Hijmans, R.J., Cameron, S.E., Parra, J.L., Jones, P.G., \& Jarvis, A. 2005. Very high resolution interpolated climate surfaces for global land areas. International Journal of Climatology, 25: 1965- 1978.

IPCC. 2007. Summary for policymakers. In: Climate change 2007: the physical science basis. Contribution of working group I to the fourth assessment report of the intergovernmental panel of climate change [Solomon, S., D. Qin, M. Manning, Z. Chen, M. Marquis, K.B. Averyt, M. Tignor and H.L. Miller (eds.)]. Cambridge University Press,
Cambridge, United Kingkom and New York, NY, USA.

Kapetsky, J.M. 2000. Present applications and future needs of meteorology and climatology data in inland fisheries and aquaculture. Agricultural and Forest Meteorology, 103: 109- 117.

Krismono \& Wahyudi, N.A. 2002. Analisis kebijakan pengelolaan KJA sebagai salah satu kegiatan pengelolaan danau dan waduk. Dalam Heruwati et al. (eds.). Analisis Kebijakan pembangunan perikanan 2001. Pusat Riset Pengolahan Produk dan Sosial Ekonomi Kelautan dan Perikanan, hlm. 7585.

Krismono, A.S.N., Krismono, \& Kartamihardja, E.S. 2001. Dampak budidaya ikan dalam keramba jaring apung terhadap peningkatan unsur $\mathrm{N}$ dan $\mathrm{P}$ di perairan Waduk Saguling, Cirata dan Jatilihur. J. Penelitian Perikanan Indonesia, 7: 22- 30.

Meisner, J.D. \& Shuter, B.J. 1992. Assessing potential effect of global climate change on tropical freshwater fishes. Geo Journal, 28(1): 21- 27.

Radiarta, I N. \& Ardi, I. 2009. Pemetaan distribusi keramba jaring apung ikan air tawar di Waduk Cirata, Jawa Barat dengan multi temporal data ALOSAVNIR- 2. J. Ris. Akuakultur, 4: 439- 446.

Radiarta, I N., Prihadi, T.H., \& Sunarno, T. 2005. Pemantauan perikanan budi daya berbasis KJA di Waduk Cirata dengan menggunakan multi- temporal data landsat 7. Warta Penelitian Perikanan Indonesia, 11: 2- 8.

Saitoh, S- I., Mugo, R., Radiarta, I N., Asaga, S., Takahashi, F.,Hirawake, T., Ishikawa, Y., Awaji, T., \& Shima, S. 2011. Some operational uses of satellite remote sensing and marine GIS for sustainable fisheries and aquaculture. ICES Journal of Marine Science, 68: 687- 695.

Soemarwoto, O., Roem, C.M., Herawati, T., \& Costa- Pierce, B.A. 1990. Water quality suitability of Saguling and Cirata reservoirs for development of floating net cage aquaculture. In: B.A. Costa- Pierce, O. Soemarwoto (eds) Reservoir Fisheries and Aquaculture Development for Resettlement in Indonesia. Manila, Philippines: ICLARM, Technical Report, 23: 18-111.

Walther, G- R., Post, E., Convey, P., Menzel, A., Parmesan, C., Beebee, T.J.C., Fromentin, JM., Hoegh- Guldberg, O., \& Barlein, F. 2002. 
Ecological responses to recent climate change, Nature, 416: 389- 395.

Xiaoyan, W., Yixun, W., Tingfang, L., Wei, H., Qiuju, H., \&Hongfen, Z. 2002. Characteris- tics of non-point source pollution in the Watershed of Miyun Reservoir, Bejing, China. Chinese Journal of Geochemistry, 21: 89-95. 